4. Frigiola A, Hughes M, Turner M, Taylor A, Marek J, Giardini A, et al. Physiologic and phenotypic characteristics of late survivors of tetralogy of Fallot repair who are free from pulmonary valve replacement. Circulation. 2013;128:1861-8.
5. Shen W-C, Chen C-A, Chang C-I, Chen Y-S, Huang S-C, Wu M-H, et al. Outflow tract geometries are associated with adverse outcome indicators in repaired tetralogy of Fallot. J Thorac Cardiovasc Surg. 2021;162:196-205.
See Article page 196.

\section{Commentary: The neglected chamber: Does the infundibulum make a difference in the long-term outcome of tetralogy of Fallot?}

\author{
Alvise Guariento, $\mathrm{MD}, \mathrm{PhD}$, and \\ Christoph Haller, MD
}

Senac, the French father of cardiac pathology, misinterpreted the description of Aristotle's third ventricle as the right ventricular infundibulum. ${ }^{1}$ The mystery around Aristotle's triventricular heart was elegantly resolved by Richard and Stella Van Praagh in $1983,{ }^{2}$ but the importance of the right ventricular infundibulum has long remained undervalued. Tetralogy of Fallot (ToF) is the congenital defect that best illustrates the role of the infundibulum, and Shen and colleagues ${ }^{3}$ add yet another twist to it.

The authors report an analysis of magnetic resonance imaging scans of patients after surgical correction of ToF with particular emphasis on the anatomy of the right ventricular outflow tract (RVOT) and pulmonary artery (PA). Measurements of lateral projections of the outflow tract were used to categorize 4 distinct geometries: tubular, with no significant stenosis along the RVOT and PA axis; pyramidal, with the narrowest segment at the distal main PA; hourglass, with the narrowest segment more proximal, but distal to the pulmonary valve annulus; and inverted trapezoid, with the narrowest segment within the RVOT. They conclude that RV remodeling was

\footnotetext{
From the Department of Cardiovascular Surgery, The Labatt Family Heart Centre, The Hospital for Sick Children, University of Toronto, Toronto, Ontario, Canada. Disclosures: The authors reported no conflicts of interest.

The Journal policy requires editors and reviewers to disclose conflicts of interest and to decline handling or reviewing manuscripts for which they may have a conflict of interest. The editors and reviewers of this article have no conflicts of interest.

Received for publication Oct 27, 2020; revisions received Oct 27, 2020; accepted for publication Oct 28, 2020; available ahead of print Nov 5, 2020.

Address for reprints: Christoph Haller, MD, Division of Cardiovascular Surgery, The Labatt Family Heart Centre, The Hospital for Sick Children, 555 University Ave, Toronto, ON, M5G 1X8 Canada (E-mail: christoph.haller@sickkids.ca).

J Thorac Cardiovasc Surg 2021;162:209-10

$0022-5223 / \$ 36.00$

Copyright (c) 2020 by The American Association for Thoracic Surgery

http://dx.doi.org/10.1016/j.jtcvs.2020.10.113
}

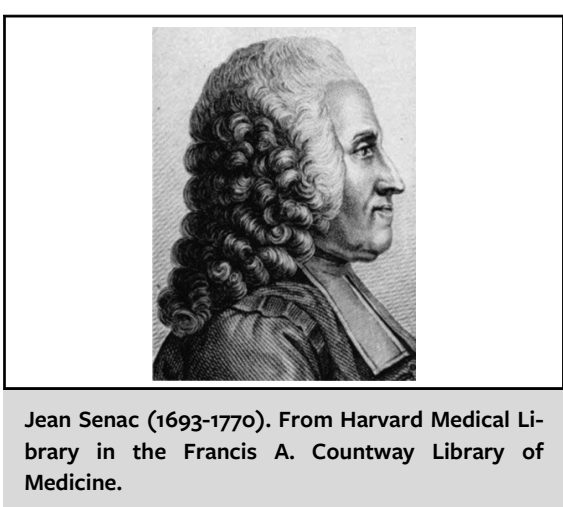

CENTRAL MESSAGE

A functional infundibulum may preserve right ventricular dimensions after surgical correction of tetralogy of Fallot.

affected by RVOT geometry with the inverted trapezoid best preserving RV end-diastolic volume indices and QRS durations.

The most frequent surgical approach to ToF nowadays remains transannular patch (TAP) reconstruction. The use of a TAP causes progressive pulmonary insufficiency and chronic right ventricular volume overload, leading to RV dilation and dysfunction. This is associated with reduced functional capacity and inevitably leads to pulmonary valve replacement in adulthood. Techniques aiming at preservation of the pulmonary valve annulus and valve function have demonstrated excellent results with low reintervention rates and reduced RV dilation compared to TAP. $^{4,5}$

The data presented by Shen and colleagues ${ }^{3}$ shed new light on the importance of the approach to the infundibulum in ToF. Although not well delineated in their article, the hourglass and especially the pyramidal geometry may represent patching of the RVOT-infundibular or transannular, respectively_leaving a large and supposedly noncontractile proximal infundibular segment followed by distal narrowing. An a- or dyskinetic infundibulum 
resulting in an aneurysm-like ventricular chamber no longer contributes to antegrade flow. ${ }^{6}$ The enlarged infundibulum in combination with distal stenosis may lead to RVOT turbulence and loss of kinetic energy further negatively contributing to RV remodeling. In contrast, an inverse trapezoid shape may reflect preservation of a relatively small (but contractile) infundibulum and supra-annular patching of the PA. Proximal stenosis leaving segments that are not actively contributing to forward flow distal also reduces regurgitation in part due to a more restrictive ventricular physiology.

Unfortunately, Shen and colleagues ${ }^{3}$ lack an analysis of the results with regard to the surgical strategy. More details on the surgical approach are needed to better understand the relationship between the chosen strategy and the subsequent morphology of the RVOT and to guide intraoperative decision making. It is also unfortunate that instead of using 3-dimensional data, only lateral-view measurements were analyzed for their main results. Although they report correlation between frontal and lateral measurements, they also stress that diameters of the RVOT and mid main PA were larger in lateral projections, but diameters of the pulmonary valve annulus and distal main PA were smaller compared with frontal projections. The hemodynamic relevance of the RVOT geometry and how it should influence surgical strategy can only be fully understood if the RVOT is captured in its entirety.

Long-term outcome of ToF is determined by the RVOT as many previous studies have already proven. Shen and colleagues ${ }^{3}$ stress once again that it is time to pay tribute to that misunderstood chamber called the right ventricular infundibulum.

\section{References}

1. Senac M. Traité de La Structure Du Coeur, de Son Action et de Ses Maladies. Paris, France: Briasson; 1749.

2. Van Praagh R, Van Praagh S. Aristotle's "triventricular" heart and the relevant early history of the cardiovascular system. Chest. 1983;84:462-8.

3. Shen W-C, Chen C-A, Chang C-I, Chen Y-S, Huang S-C, Wu M-H, et al. Outflow tract geometries are associated with adverse outcome indicators in repaired tetralogy of Fallot. J Thorac Cardiovasc Surg. 2021;162:196-205.

4. Vida VL, Guariento A, Zucchetta F, Padalino M, Castaldi B, Milanesi O, et al. Preservation of the pulmonary valve during early repair of tetralogy of Fallot: surgical techniques. Semin Thorac Cardiovasc Surg Pediatr Card Surg Annu. 2016; 19:75-81.

5. Hickey E, Pham-Hung E, Halvorsen F, Gritti M, Duong A, Wilder T, et al. Annulus-sparing tetralogy of Fallot repair: low risk and benefits to right ventricular geometry. Ann Thorac Surg. 2018;106:822-9.

6. McKenzie ED, Maskatia SA, Mery C. Surgical management of tetralogy of Fallot: in defense of the infundibulum. Semin Thorac Cardiovasc Surg. 2013;25: 206-12.

\section{Commentary: More is not always better}

\section{Tracy R. Geoffrion, MD, MPH}

Advanced cardiac imaging provides ever-increasing amounts of anatomic and physiologic data on congenital heart disease. As with many things in life, more is not always better. To surgeons, more data are better when they inform our decision making and thus improve surgical outcomes.

\footnotetext{
From the Division of Cardiothoracic Surgery, Department of Surgery, Children's Hospital of Philadelphia, Philadelphia, $\mathrm{Pa}$.

Disclosures: The author reported no conflicts of interest.

The Journal policy requires editors and reviewers to disclose conflicts of interest and to decline handling or reviewing manuscripts for which they may have a conflict of interest. The editors and reviewers of this article have no conflicts of interest.

Received for publication Sept 30, 2020; revisions received Sept 30, 2020; accepted for publication Sept 30, 2020; available ahead of print Oct 9, 2020.

Address for reprints: Tracy R. Geoffrion, MD, MPH, Division of Cardiothoracic Surgery, Department of Surgery, Children's Hospital of Philadelphia, 3401 Civic Center Blvd, Suite 8574, Philadelphia, PA 19104 (E-mail: tracygeoffrion@gmail.com).

J Thorac Cardiovasc Surg 2021;162:210-1

$0022-5223 / \$ 36.00$

Copyright (c) 2020 by The American Association for Thoracic Surgery

http://dx.doi.org/10.1016/j.jtcvs.2020.09.127
}

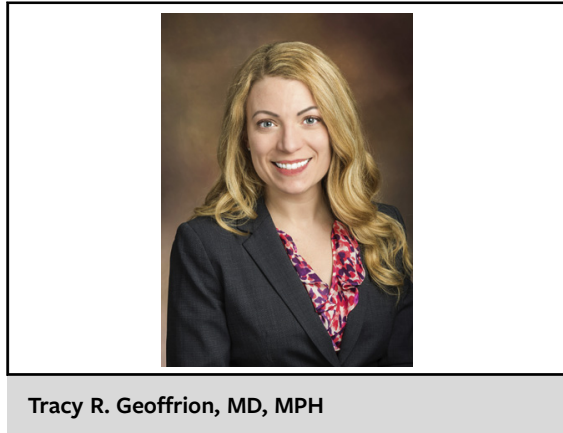

CENTRAL MESSAGE

Advanced cardiac imaging pro-

vides ever-increasing amounts of

data on congenital heart disease.

Practical application of these

data by surgeons is not always

straightforward. 